\title{
Review
}

\section{Oral tolerance in disease}

\begin{abstract}
Preface
The induction of immunological unresponsiveness by feeding soluble antigens, termed oral tolerance, has been attracting considerable attention as a potential therapy for a variety of systemic inflammatory disorders. However, the physiological role of this phenomenon is in maintaining gastrointestinal homoeostasis and preventing immunopathology in the gut. This review will discuss the mechanisms of oral tolerance in the context of the structure and function of the gut associated lymphoid tissues (GALT), outline how defects in oral tolerance can lead to immunopathology and indicate its therapeutic potential.
\end{abstract}

\section{Introduction}

The large surface area of the gastrointestinal tract is covered by a single layer of columnar epithelium which allows efficient absorption of nutrients, but also offers a potential portal of entry for microbial pathogens. Thus, a highly structured immune network, the GALT has evolved as an integral part of the intestine to provide protection against pathogenetic microorganisms. ${ }^{1}$ However, the intestinal immune system is faced with the dilemma of discriminating between antigens with no pathogenetic potential (dietary proteins and commensal organisms) and antigens associated with potentially harmful microbes. It has long been recognised that the encounter of dietary antigens by the immune system normally leads to antigen specific tolerance. ${ }^{2}$ This phenomenon has been termed oral tolerance and can be induced by most soluble antigens. ${ }^{3}{ }^{4}$ The consequences of the apparent breakdown of oral tolerance to dietary antigens are exemplified by diseases such as gluten sensitive enteropathy (coeliac disease) and other food sensitive enteropathies. ${ }^{4}$ The intestinal immune system must also maintain stringent control over responses to its resident bacterial flora. These organisms are essential for normal intestinal function, yet they constitute a potential challenge to the integrity of the host. Recent evidence suggests that the breakdown of intestinal immunoregulation of responses to endogenous flora may be the underlying cause of inflammatory bowel diseases such as ulcerative colitis and Crohn's disease..$^{5-8}$ Understanding the mechanisms responsible for oral tolerance may lead to new treatment strategies for such conditions. In addition, antigen feeding may provide a potential immunotherapy for a number of systemic inflammatory disorders.

\section{Immunological tolerance}

The ability of the vertebrate immune system to generate antigen specific responses to a plethora of foreign antigens depends on the expression of a large number of unique antigen receptors by lymphocytes. However, inherent in this strategy is the danger of recognition of self or useful exogenous antigens and the possibility of autoimmunity or immunopathology. Therefore, a number of mechanisms exist to prevent this by the induction of immunological tolerance.

The best understood mechanism of immunological tolerance is central tolerance established in the primary lymphoid organs, thymus and bone marrow via the physical deletion of self reactive T and B cells. ${ }^{9}$ However, not all self antigens are represented in the primary lymphoid organs, whereas others may be restricted to certain peripheral tissues or particular periods of life after antigen specific lymphocytes have already seeded the periphery (puberty, pregnancy, lactation, aging). Therefore, central tolerance must be complemented by additional mechanisms of peripheral tolerance. Unresponsiveness of $\mathrm{T}$ cells in the periphery may be achieved in a number of ways. Firstly, the $T$ cell may never encounter the antigen in an immunologically relevant form and thus be ignorant of it. Secondly, the $\mathrm{T}$ cell may encounter the antigen in circumstances that result in the subsequent functional or actual elimination of the cell (anergy or deletion). Finally, regulatory cells or mediators may be induced that can modify the immune response.

Whether antigen induces tolerance or immunity in the periphery is probably dependent on costimulatory signals provided to the $\mathrm{T}$ cells by antigen presenting cells (APC). Early studies established that the same antigen can be either tolerogenic or immunogenic depending on its form. Administration of a soluble, monomeric antigen in the absence of coadministered adjuvant usually results in unresponsiveness to subsequent exposure to the same antigen. ${ }^{10} 11$ By contrast, administration of antigen in particulate form or in the presence of an adjuvant leads to a productive immune response probably due to the induction of inflammatory cytokines (tumour necrosis factor (TNF), interleukin (IL) 1, IL-6, etc) and upregulation of costimulatory molecules (B7-1, B7-2, CD40 etc) on APC. ${ }^{12}$

Oral tolerance is a special case of peripheral immunological tolerance. The precise immunological basis remains controversial, reflecting complex interactions between digestion, specialised antigen uptake and a variety of immunoregulatory mechanisms

\section{Immune regulation in the intestine}

BARRIER FUNCTION AND FILTRATION

Clonal ignorance of $\mathrm{T}$ cells would result if immunologically relevant forms of antigens did not gain access to the immune system via the gut. This might simply result from the destruction of immunological epitopes by the nonspecific effects of digestion, or because the physical barrier of the intestinal epithelium and its associated mucus layer prevents antigen access to APC. However, this possibility is argued against by the fact that immunologically relevant protein can be detected in serum within minutes of ingestion and indeed this material may be essential for the development of oral tolerance. ${ }^{13-15}$ It seems more likely that the barrier effect, if any, of the gut is to filter aggregated antigens resulting in monomeric forms being available systemically. The physical barrier may also hinder uptake of

Abbreviations used in this paper: GALT, gut associated lymphoid tissue; APC, antigen presenting cell; TNF, tumour necrosis factor; IL, interleukin; LPS, lipopolysaccharide; TcR, T cell receptor; OVA, ovalbumin; MBP, myelin basic protein; TNFR, tumour necrosis factor receptor; TGF, transforming growth factor; CTL, cytotoxic T lymphocytes; IEL, intraepithelial lymphocyte; CMI, cell mediated immune; IFN, interferon; IBD, inflammatory bowel disease; SCID, severe combined immunodeficiency; KLH, keyhole limpet haemocyanin; IDDM, insulin dependent diabetes melitus; TNBS, trinitrobenzene sulphonic acid. 
bacteria with their associated adjuvant activity, an effect enhanced by the ability of the liver to remove remaining "free" adjuvant, such as lipopolysaccharide (LPS). Thus, antigen passing across the gut wall into the circulation may be in a highly soluble, monomeric form in the absence of the inflammatory signals required for costimulation. Based on knowledge from other models of peripheral tolerance, it would be expected that presentation of this form of antigen would result in T cell anergy. That this occurs in oral tolerance is supported by findings that the impaired ability of cells to respond to antigen in vitro is restored by exogenous IL-2, indicating the continued presence of antigen reactive T cells. ${ }^{16}$ More recent work has confirmed this idea more directly by showing that adoptively transferred antigen specific $\mathrm{T}$ cell receptor ( $\mathrm{TcR}$ ) transgenic $\mathrm{T}$ cells persist in vivo following feeding, but are hyporesponsive to antigen when restimulated in vitro. ${ }^{17}$

Antigen specific $\mathrm{T}$ cells could also be inactivated by apoptosis mediated clonal deletion. This occurs in other systems when peripheral tolerance is induced by exogenous superantigen $\mathrm{s}^{18}$ or after administration of conventional antigens to TcR transgenic animals. ${ }^{19}$ Under these conditions, $\mathrm{T}$ cell apoptosis may result from massive release of toxic cytokines, growth factor deprivation, or direct induction of programmed cell death. Clonal deletion of CD4+ $\mathrm{T}$ cells via apoptosis in vivo has been demonstrated following oral administration of soluble chicken ovalbumin (OVA) to TcR transgenic mice, ${ }^{19}$ although this was not observed after feeding myelin basic protein (MBP) to appropriate transgenic mice. ${ }^{20}$ Furthermore, the physiological relevance of studying immune responses in fully transgenic animals is unclear. The more physiologically relevant system in which small numbers of identifiable $\mathrm{TcR}$ transgenic $\mathrm{T}$ cells are adoptively transferred into normal syngeneic recipients ${ }^{21}$ has yielded conflicting results ${ }^{172}$ with one study finding $\mathrm{T}$ cell deletion after feeding very large doses of antigenic peptide while another reported no evidence of deletion in mice fed more conventional tolerogenic doses of OVA protein. The fact that oral tolerance can be induced normally in lpr mice (Garside, Steel and Mowat, unpublished observations) argues against a role for fas dependent apoptosis in the intact animal, although recent studies indicate a possible role for TNF receptor (TNFR) mediated apoptosis in oral tolerance (Mowat, Viney and Garside, unpublished observations).

\section{Regulatory $\mathbf{T}$ cells}

An alternative possibility to clonal inactivation of individual specific $T$ cells is the induction of regulatory cells. Many early studies found that tolerance induced by feeding could be transferred by cells that were generally found to be $\mathrm{CD} 8+{ }^{23}$ and it was proposed that oral tolerance was a result of the activation of antigen specific CD8+ suppressor $\mathrm{T}$ cells. ${ }^{23}$ It has also been proposed that regulatory CD8+ T cells induced in this way may mediate "bystander suppression" via the production of inhibitory cytokines such as transforming growth factor (TGF) $\beta$ which can exert non-specific suppressive effects on other antigen reactive cells in the vicinity, irrespective of their specificity. ${ }^{24}$ In recent years, the existence of a discrete population of regulatory CD8+ cells has been doubted and an alternative way in which classic CD8+ T cells could act in tolerance is suggested by findings that MHC class I restricted cytotoxic $\mathrm{T}$ lymphocytes (CTL) can modulate antigen specific immune responses via the lysis of antigen bearing APC or idiotype bearing CD4+ T cells. ${ }^{25}$ Studies designed to assess the role of CD8+ CTL in oral tolerance have provided conflicting results, with tolerance, priming or ignorance of these cells in response to fed antigen all being reported..$^{26-28}$

One further possibility is that the regulatory CD8+ T cells induced by feeding antigen may belong to the $\gamma \delta \mathrm{TcR}$ expressing subset of lymphocytes. $\mathrm{CD} 8+\gamma \delta+\mathrm{T}$ cells are relatively abundant within the intraepithelial lymphocyte (IEL) compartment ${ }^{29}$ and their depletion with monoclonal antibodies or by genetic manipulation has shown that these cells may also be essential for the development of oral tolerance with a range of doses of fed antigen. ${ }^{30}$ Regulatory $\gamma \delta$ cells have also been implicated in tolerance induced by the intranasal route. ${ }^{31}$ The nature of the antigen recognised and how these cells act is unclear, but one recent report suggests that they may interact with $\alpha \beta \mathrm{T}$ cells. ${ }^{32} \mathrm{~A}$ further complication to understanding the role of $\gamma \delta$ cells in regulating mucosal immune responses is their putative homoeostatic role in maintaining epithelial integrity. ${ }^{33}$

The requirement for CD8+ T cells in oral tolerance has been examined using genetically engineered CD8 or beta2-microglobulin knockout mice ${ }^{34} 35$ and in mice treated with anti-CD8 antibodies. ${ }^{26}{ }^{35-37}$ In all these studies, oral tolerance is induced normally, indicating that there is no absolute requirement for CD8 $+\mathrm{T}$ cells in the induction or maintenance of systemic tolerance.

In contrast to the contentious role of CD8+ $T$ cells, most workers agree that CD4+ T cells are essential for oral tolerance. Oral tolerance is abrogated if CD4+ $\mathrm{T}$ cells are depleted in vivo ${ }^{2637}$ and CD4 knockout mice do not become tolerised to contact sensitising agents, even when the effector response is mediated by CD8+ T cells. ${ }^{38}$ It has also been reported that CD $4+\mathrm{T}$ cells can transfer oral tolerance in vivo. ${ }^{2436}$ The original theory to explain these results was that oral tolerance reflected the downregulation of T helper 1 (Th1) CD4+ cells by T helper 2 (Th2) cells, an idea compatible with the fact that it is easier to induce and maintain oral tolerance of cell mediated immune (CMI) responses in comparison with humoral responses. ${ }^{34}$ However, oral tolerance to OVA can suppress both Th1 and Th2 responses quite adequately ${ }^{40}$ and normal oral tolerance can be induced in the absence of Th2 cells in both IL-4 knockout mice ${ }^{40}$ and in mice treated with anti-IL-4 antibodies, even when tolerance is associated with increased production of IL- $4 .{ }^{41}$ In addition, the highly Th2 dependent production of $\mathrm{IgE}$ is amongst the most sensitive of effector functions to the induction of oral tolerance. ${ }^{42} \mathrm{It}$ seems reasonable to expect that Th2 cells would be susceptible to tolerance, given the fact that Th2 mediated responses may be equally as pathogenetic as Th1 responses. ${ }^{434}$ More recently, the role of CD4 $\mathrm{T}$ cells as active mediators of oral tolerance has been explained by the presence of populations of regulatory T helper 3 (“Th3") or $\mathrm{T}$ regulatory 1 ("Tr1") cells which produce suppressive cytokines (see later) and which can inhibit Th1 cell mediated immunopathologies such as experimental autoimmune encephalomyelitis and colitis. ${ }^{24}$

\section{Regulatory cytokines}

Although distinct subpopulations of $\mathrm{T}$ cells have been implicated in oral tolerance, it is also possible that it may be caused by the preferential production of individual inhibitory cytokines in response to fed protein. Those which have received most interest are IL-4, IL-10, interferon (IFN) $\gamma$, and TGF- $\beta$.

As we have noted, IL-4 does not seem to be essential, despite some evidence for its preferential upregulation. ${ }^{24}$ As IL-10 suppresses Th1 activity via downregulation of the expression of costimulatory molecules and IL-12 production by APC, ${ }^{45}$ it was an attractive candidate as a mediator of oral tolerance, particularly if this was mediated by Th2 cells. Initial reports suggested that the production of 
IL-10 was enhanced in oral tolerance, ${ }^{19} 202436$ whereas IL-10 producing "Th3" clones can be isolated from animals tolerised by feeding $\mathrm{MBP} .{ }^{24}$ More recently, IL-10 dependent OVA specific TcR transgenic $\mathrm{T}$ lymphocytes have been shown to mediate non-specific bystander suppression of experimental colitis when adoptively transferred in vivo and activated by feeding OVA. ${ }^{5}$ However, we have found notable suppression of this cytokine in mice fed $\mathrm{OVA}^{40}$ and normal oral tolerance occurs in mice depleted of IL-10. ${ }^{47}$ Thus, the role of this cytokine in oral tolerance remains unclear.

The CD $8+\gamma \delta+\mathrm{T}$ cells which transfer nasal tolerance to soluble OVA produce IFN- $\gamma$ and enhanced IFN- $\gamma$ production is a feature of some models of mucosal tolerance, in which there is suppression of IL-4 mediated $\operatorname{IgE}$ responses. ${ }^{31}$ Also, priming of IFN- $\gamma$ production has been noted very early after feeding ${ }^{48}$ (Steel, Mowat and Garside, unpublished observations). These results are consistent with the cytostatic properties of IFN- $\gamma$, ${ }^{49}$ the preservation of its production in mice tolerised by parenteral injection of staphylococcal enterotoxin $\mathrm{B}^{20}$ and with its central role in some models of $\mathrm{T}$ cell anergy in vitro. ${ }^{50}$ However, most workers find that the production of IFN- $\gamma$ is highly susceptible to the suppressive effects of feeding antigen and our recent work indicates that oral tolerance can be induced in IFN- $\gamma$ depleted and IFN- $\gamma \mathrm{R}$ knockout mice (Steel, Garside and Mowat, unpublished observations). Similar findings have been made by others. ${ }^{34}$

TGF- $\beta$ is the mediator receiving most current attention. Abundant in the normal intestine, ${ }^{52}$ it is produced by cells of both haemopoietic and epithelial origin and is important in regulating epithelial homoeostasis and IgA switching. ${ }^{53}$ TGF- $\beta$ also has well documented suppressive effects on many aspects of the immune response. ${ }^{54}$ Increased production of this cytokine has been reported in a number of models of oral tolerance ${ }^{55}$ and TGF- $\beta$ secreting $\mathrm{T}$ cell clones can be produced from animals tolerised in this way. ${ }^{20}{ }^{24}$ Furthermore, the bystander suppressive effects exerted by these cells in vitro and in vivo can be prevented with anti-TGF- $\beta .{ }^{56}$ Local TGF- $\beta$ production has also been associated with the prevention of experimental colitis in a number of models ${ }^{57}{ }^{58}$ and the recently described regulatory "Th3" and "Tr1" cells (see earlier) are a potent source of this cytokine..$^{520}$ Recent studies suggest that TGF- $\beta$ and the IL-12/IFN- $\gamma$ pathway play opposing roles in intestinal immune regulation and that modulation of these cytokines may be the key to induction of mucosal immunity or tolerance, or both..$^{59}$ However, increased TGF- $\beta$ production is not a universal finding in all models of mucosal tolerance ${ }^{3960}$ and the role of this cytokine requires further investigation.

\section{Consequences of the loss of immunoregulation in the gut}

The importance of oral tolerance for preventing hypersensitivity to dietary proteins is evidenced by the presence of unusual immune responses to gluten in patients with coeliac disease and by experimental findings that abrogation of oral tolerance allows the development of enteropathy after oral antigen challenge. ${ }^{6162}$ More recently, it has become apparent that inflammatory bowel diseases (IBD) such as Crohn's disease and ulcerative colitis may reflect a breakdown in an analogous state of tolerance to commensal bacteria. ${ }^{7863}$ This is consistent with the frequent usefulness of antibiotics in the treatment of human IBD and with the fact that all of the experimental models of IBD can be prevented by antibiotics or a germ-free environment. However, in most cases, no specific pathogen can be identified. As there is evidence in mice and man for tolerance to autologous flora in normal individuals and a breakdown of this tolerance occurs in IBD, ${ }^{64}{ }^{65}$ it may be that potentially pathological responses to components of the intestinal flora do occur under physiological conditions but these are suppressed by the immunoregulatory mechanisms outlined earlier.

Experimental models confirm that IBD can occur as a result of defective immunoregulation in IL-2, IL-10 and $\mathrm{TcR} \alpha$ knockout mice ${ }^{66-68}$ and in severe combined immunodeficiency (SCID) mice adoptively transferred with CD45RB ${ }^{\text {hi }}$ CD4+ T cells. ${ }^{6}$ The nature of the regulatory defect revealed in these spontaneous models of IBD in knockout mice is unknown, but in SCID mice adoptively transferred with $\mathrm{CD}_{45 \mathrm{RB}^{\mathrm{hi}}} \mathrm{CD} 4+\mathrm{T}$ cells ${ }^{6}$ IBD is prevented by IL-10 dependent TGF- $\beta$ production by a subset of CD $45 \mathrm{RB}^{\text {lo }} \mathrm{CD} 4+\mathrm{T}$ cells. ${ }^{57}$ An analogous population of IL-10 dependent "Tr1" cells which produce IL-10 and TGF- $\beta$ have been shown to prevent CD $45 \mathrm{RB}^{\mathrm{hi}} \mathrm{CD} 4+$ $\mathrm{T}$ cell induced colitis in a non-specific bystander manner. ${ }^{5}$ TGF- $\beta$ is also required for the ability of feeding hapten to prevent colitis induced by rectal administration of trinitrobenzene sulphonic acid (TNBS).$^{58}$

Thus, a simple lack of regulatory mediators or cells in the gut might lead to a breakdown in oral tolerance due to unlimited inflammation in a previously normal gut. Alternatively, a breakdown in barrier function might allow access of inflammatory bacterial products to the local immune system, overwhelming normal regulation. This possibility is supported by experimental models in which the epithelial barrier has been disrupted. Early studies showed that direct disruption of the epithelial barrier using a variety of chemical treatments (e.g. carrageenan) resulted in the induction of a local inflammatory response similar to that seen in human IBD. ${ }^{69}$ Compromising epithelial integrity by expressing a dominant negative mutant of the $\mathrm{N}$-cadherin molecule ${ }^{70}$ or by knockout of the epithelial cytoskeletal structural protein keratin $8^{71}$ produces spontaneous IBD, and mice lacking intestinal trefoil factor are unusually susceptible to colitis induced with dextran sodium sulphate. ${ }^{72}$ Bacteria could also contribute to the breakdown of oral tolerance and induction of IBD by disturbing barrier function. For instance, it has been proposed that excessive hydrogen sulphide production by the sulphate reducing bacteria within the colonic flora of patients with ulcerative colitis (see Sartor and colleagues ${ }^{8}$ for review) may contribute to the pathology.

It is easy to imagine that once the initial breakdown in tolerance has been established, the inflammatory state will be perpetuated by bacteria invading the mucosa, permitting normally tolerogenic responses to most luminal antigens to be modified into immunogenic responses. Persistent inflammation would further damage the epithelium and drive the vicious cycle (fig 1 ). We would predict that a combination of defects in barrier function, immunoregulation and/or inflammatory mediator production will be required for a breakdown in gastrointestinal homoeostasis to occur. This is consistent with the polygenic nature of IBD and also suggests that the most successful immunotherapy requires a combination of anti-inflammatory therapy, antibiotics and reinduction of tolerance. The

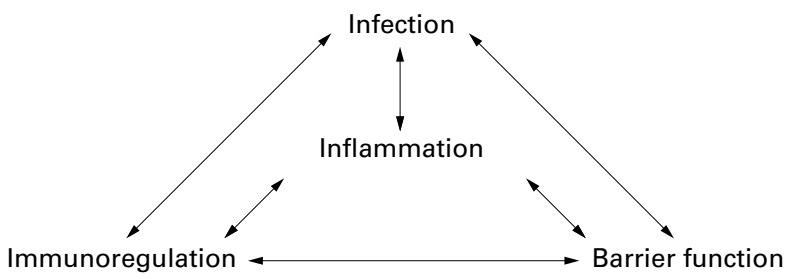

Figure 1 Relation between infection, immunoregulation, barrier function, and inflammation. 
Table 1 Suppression of autoimmunity by oral tolerance

\begin{tabular}{lll}
\hline Model/trial & Protein fed & References \\
\hline Animal models & MBP, PLP & $16,20,54,73-76$ \\
EAE & CII & $77,78,79-84$ \\
Arthritis (CII, AA) & S-Ag, IRBP & $85-89$ \\
Uveitis & AChR & $90-93$ \\
Myasthenia gravis & Insulin, GAD & $94-96$ \\
Diabetes (NOD mouse) & Alloantigen, MHC & $72,97,98$ \\
Transplantation & peptide & \\
Thyroiditis & Thyroglobulin & 99,100 \\
Colitis & Haptenised colonic & 57 \\
& proteins & \\
Human disease trials & Bovine myelin & Weiner HL, personal \\
Multiple sclerosis & Chicken type II collagen & $77,101,102$ \\
& Bovine S-Ag & 103 \\
Rheumatoid arthritis & Human insulin & 104 \\
Uveitis & &
\end{tabular}

AChR, acetylcholine receptor; CII, type II collagen; EAE, experimental allergic encephalomyelitis; IRBP, interphotoreceptor binding protein; MBP, myelin basic protein; MHC, major histocompatibility complex; NOD, non-obese diabetic; PLP, proteolipid protein.

recent demonstration of bystander suppression of experimental colitis ${ }^{5}$ by nominal antigen specific regulatory $\mathrm{T}$ cells extends the prospects of devising such regimens considerably.

\section{Oral tolerance as a therapy for systemic immunopathology}

A number of experimental models have shown the efficacy of oral tolerance in preventing or treating systemic inflammation. ${ }^{34}$ Although all of the mechanisms we have outlined might be potentially useful, an active suppressor mechanism would have most advantages, as it might allow suppression of responses to an unrelated "bystander" antigen. Conversely, antigen induced inactivation of potentially reactive lymphocytes due to deletion or functional anergy might imply a more stable, long-lasting tolerance which is less susceptible to modification by other immune responses. However, how the latter mechanisms would maintain unresponsiveness throughout the animal, particularly in the face of repopulation with naive cells from the thymus, remains unclear and repeated administration of the specific tolerising antigen might be necessary. Studies in experimental animals suggest it may be possible to induce either of these mechanisms selectively by varying the antigen feeding regimen. Thus repeated low doses of antigen are proposed to induce active suppressor mechanisms, ${ }^{3}$ whereas higher doses may favour induction of anergy/deletion. ${ }^{34}$ Tailored immunotherapy may be feasible in this way.

Many studies have demonstrated the effectiveness of orally administered antigens in rat and mouse models of autoimmune disease, including experimental allergic encephalomyelitis, arthritis induced by collagen, adjuvant or pristane, uveoretinitis, myaesthenia gravis, thyroiditis and insulin dependent diabetes (table 1). In addition, it has been possible to suppress allograft rejection by feeding allogeneic cells or MHC peptides. ${ }^{73}$ A number of features of these studies are of clinical significance. Firstly, it has been possible to inhibit established disease by feeding antigen, although it is often necessary to administer large amounts of antigen on repeated occasions to achieve this. Secondly, the induction of bystander suppression has been shown frequently, allowing the use of antigen which is not necessarily the autoantigen which initiates the disease. Finally, several groups have achieved disease suppression by feeding defined epitope peptides, raising the possibility of using engineered small molecules for this purpose.

\section{Oral tolerance in humans}

Oral tolerance has been demonstrated experimentally in human volunteers fed repeated doses of keyhole limpet haemocyanin $(\mathrm{KLH})$. Under these conditions, antibody responses to subsequent parenteral challenge were not altered, but the KLH fed individuals had suppressed cell mediated immune responses. ${ }^{105}$ Nasal KLH has also been reported to induce tolerance in humans. ${ }^{106}$ Formal clinical trials have also been carried out in patients with multiple sclerosis, rheumatoid arthritis, uveitis, and insulin dependent diabetes melitus (IDDM), with initially encouraging results and no side effects reported. ${ }^{104}$ In addition, one study indicated that feeding bovine myelin to patients with multiple sclerosis resulted in the preferential appearance of TGF- $\beta$ secreting "Th3"-like cells in peripheral blood, rather similar to findings reported in analogous rodent experiments. ${ }^{107}$ It should be noted, however, that only a small subset of HLA-DR2+ male patients with multiple sclerosis responded to antigen feeding ${ }^{108}$ and a more recent phase III trial in multiple sclerosis did not show statistically significant differences between placebo and myelin fed groups (AutoImmune Inc., Lexington, MA, USA). Similarly, despite early reports that feeding chicken collagen led to statistically significant clinical improvement in adult and juvenile rheumatoid arthritis, ${ }^{109}$ (Weiner HL, personal communication) a subsequent European trial found no evidence of a significant difference between test and placebo groups in patients receiving larger doses of bovine type II collagen $(1-10 \mathrm{mg}) .{ }^{101}$ This discrepancy may reflect dose dependent effects, as a recently completed multicentre double blind phase II trial of feeding a range of doses of chicken type II collagen showed statistically significant positive effects in the group treated with the lowest dose $(20 \mu \mathrm{g}) .{ }^{102}$ These results are consistent with animal studies of orally administered type II collagen in which protection against adjuvant and antigen induced arthritis and bystander suppression was observed only at the lower doses. ${ }^{77} 78$ In uveitis, no significant effects of feeding bovine uveal S-antigen were observed. ${ }^{110}$ Currently, other trials are underway feeding recombinant human insulin to newonset diabetic patients, as well as in patients at risk of developing IDDM. The results of all these trials are clearly anticipated with great interest, as they will give important pointers to the future potential of the approach. Given the notable dose and antigen dependent effects which have been described in animals, it is perhaps not surprising that more clear cut results have not been obtained from the early clinical studies, which were obliged to use somewhat arbritrary doses and preparations of antigen. Important issues will be the conditions required for induction of bystander suppression and whether the phenomenon proves to be a universal phenomenon, as causative autoantigens cannot be identified with certainty in most human disease. Finally, for practical use in humans, it may be essential to exploit approaches which seem to enhance the induction of tolerance after mucosal administration of small doses of antigen, including the use of the nasal route, ${ }^{111}$ or conjugation to the $\mathrm{B}$ subunit of cholera toxin. ${ }^{103}$ Alternatively, it may be feasible to obtain large amounts of mucosally delivered tolerogen by production in transgenic plants. ${ }^{112}$

\section{Conclusions}

Thus, oral tolerance is an important physiological phenomenon with potential therapeutic applications. The interactions between barrier, immunoregulation and local antigen also provides an intriguing system to study the biology of mucosal immune responses. 
P GARSIDE A McI MOWAT

Department of Immunology, University of Glasgow, Western Infirmary, Glasgow G11 6NT, UK

Department of Microbiology,

University of Minnesota,

Center for Immunology,

420 Delaware Street SE,

Minneapolis, MN 55455, USA

1 Mowat AMcI, Viney J. The anatomical basis of intestinal immunity. Immunol Rev 1997;156:145-66.

2 Wells HG, Osborne TB. The biological reactions of the vegetable proteins. I. Anaphylaxis. $\mathcal{F}$ Infect Dis 1911;8:66-124

3 Garside P, Mowat AMcI. Mechanisms of oral tolerance. Crit Rev Immunol 1996;17:119-37.

4 Mowat AMcI, Weiner HL. Oral tolerance: basic mechanisms and clinical implications. In: Ogra PL, Mestecky J, Lamm ME, et al, eds. Handbook of mucosal immunology. 2nd edn. San Diego: Academic Press, 1998.

5 Groux H, O'Garra A, Bigler M, et al. A CD4+ T-cell subset inhibits antigenGroux H, O'Garra A, Bigler M, et al. A CD4+ T-cell subset inhibits antigen
specific T-cell responses and prevents colitis. Nature 1997;389:737-42.

6 Powrie F. T cells in inflammatory bowel disease: protective and pathogenic roles. Immunity 1995;3:171-4.

7 Elson CO, Sartor BR, Tennyson GS, et al. Experimental models of inflammatory bowel disease. Gastroenterology 1995;109:1344-67.

8 Sartor RB, Rath HC, Sellon RK. Microbial factors in chronic intestinal inflammation. Curr Opin Gastroenterol 1996;12:327-33

9 Schwartz RH. Acquisition of self-tolerance. Cell 1989;57:1073-81.

0 Dresser, DW. Effectiveness of lipid and lipidophilic substances as adjuvants. Nature 1961;191:1169-71.

11 Vives J, Parks DE, Weigle WO. Immunologic unresponsiveness after gastric administration of human gamma-globulin: antigen requirements and cellular requirements. F Immunol 1980;125:1811-16.

12 Pape KA, Khoruts A, Mondino A, et al. Inflammatory cytokines enhance the in vivo clonal expansion and differentiation of antigen-activated CD4+ T cells. F Immunol 1997;159:591-8.

13 Swarbrick ET, Stokes CR, Soothill JF. Absorption of antigens after oral immunization and the simultaneous induction of specific systemic tolerance. Gut 1986;20:121-5.

14 Husby S, Jensenius JC, Svehag SE, et al. Passage of undergraded dietary antigen into the blood of healthy adults. Further characterization of the
kinetics of uptake and the size distribution of the antigen. Scand f Immunol kinetics of uptake

15 Husby S, Foged N, Høst A, et al. Passage of dietary antigens into the blood of children with coeliac disease. Quantification and size distribution of absorbed antigens. Gut 1987;28:1062-72.

16 Whitacre CC, Gienapp IE, Orosz CG, et al. Oral tolerance in experimental autoimmune encephalitis. III. Evidence for clonal anergy. F Immunol 1991; 147:2155-63.

17 Van Houten N, Blake SF. Direct measurement of anergy of antigen-specific T cells following oral tolerance induction. F Immunol 1996;157:1337-41.

18 Baschieri S, Lees RK, Lussow AR, et al. Clonal anergy to staphylococcal enterotoxin B in vivo: selective effects on $\mathrm{T}$ cell subsets and lymphokines. Eur F Immunol 1993;23:2661-6.

19 Chen Y, Inobe J-I, Marks R, et al. Peripheral deletion of antigen-reactive T cells in oral tolerance. Nature 1995;376:177-80.

20 Chen Y, Inobe J-I, Kuchroo VK, et al. Oral tolerance in myelin basic protein T-cell receptor transgenic mice: suppression of autoimmune encephalomyT-cell receptor transgenic mice: suppression of autoimmune encephalomyUSA 1996;93:388-91.

21 Kearney ER, Pape KA, Loh DY, et al. Visualization of peptide-specific T cell immunity and peripheral tolerance induction in vivo. Immunity 1994;1: 327-39.

22 Chen Y, Inobe J-I, Weiner HL. Inductive events in oral tolerance in the TcR transgenic adoptive transfer model. Cell Immunol 1997;178:62-8.

23 Mowat AM. The regulation of immune responses to dietary protein antigens. Immunol Today 1987;8:93-8.

24 Chen Y, Kuchroo VK, Inobe J, et al. Regulatory T cell clones induced by oral tolerance: suppression of autoimmune encephalomyelitis. Science 1994; 265:1237-40.

25 Rock KL, Rothstein L, Fleischacker C, et al. Inhibition of class I and class II MHC-restricted antigen presentation by cytotoxic $\mathrm{T}$ lymphocytes specific for an exogenous antigen. F Immunol 1992;148:3028-33.

26 Garside P, Steel M, Liew FY, et al. CD4+ but not CD8+ T cells are required for the induction of oral tolerance. Int Immunol 1995;7:501-4.

27 von Herrath MG, Dryberg T, Oldstone MB. Oral insulin treatment suppresses virus-induced antigen-specific destruction of $\beta$ cells and suppresses virus-induced antigen-specific destruction of $\beta$ cells and
prevents autoimmune diabetes in transgenic mice. $\mathcal{F}$ Clin Invest 1996;98: prevents

28 Blanas E, Carbone FR, Allison, J, et al. Induction of autoimmune diabetes by oral administration of autoantigen. Science 1997;274:1707-9.

29 Lefrancois L. Basic aspects of intraepithelial lymphocyte immunobiology. In: Ogra PL, Mestecky J, Lamm ME, et al. Handbook of mucosal immunology. 2nd edn. San Diego: Academic Press, 1998.

$30 \mathrm{Ke} \mathrm{Y,} \mathrm{Kapp} \mathrm{JA.} \mathrm{Oral} \mathrm{antigen} \mathrm{inhibits} \mathrm{priming} \mathrm{of} \mathrm{CD8}{ }^{+} \mathrm{CTL}, \mathrm{CD} 4^{+} \mathrm{T}$ cells and antibody responses while activating $\mathrm{CD}^{+}$suppressor $\mathrm{T}$ cells. $\mathcal{F}$ Immunol 1996;156:916-21.

31 McMenamin C, Pimm M, McKersey M, et al. Regulation of IgE responses to inhaled antigen in mice by antigen-specific $\gamma \delta$ T cells. Science $1994 ; 265$ : 1869-71.

32 Wildner G, Thurau SR. Orally induced bystander suppression in experimental autoimmune uveoretinitis occurs only in the periphery and not in the eye. Eur f Immunol 1995;25:1292-7.

33 Boismenu R, Havran WL. Modulation of epithelial cell growth by intraepithelial $\gamma \delta$ T cells. Science 1994;266:1253-5.

34 Lycke N, Bromander A, Ekman L, et al. The use of knockout mice in studies of induction and regulation of gut mucosal immunity. Mucosal Immunology Update 1995;3:1-8.
35 Vistica BP, Chanaud NP, Felix N, et al. CD8 T-cells are not essential for the induction of "low dose" oral tolerance. Clin Immunol Immunopathol 1996;78:196-202.

36 Chen Y, Inobe J-I, Weiner HL. Induction of oral tolerance to myelin basic protein in CD8-depleted mice: Both $\mathrm{CD} 4^{+}$and $\mathrm{CD} 8^{+}$cells mediate active suppression. F Immunol 1995;155:910-16.

37 Barone KS, Jain SL, Michael JG. Effect of in vivo depletion of $\mathrm{CD}_{4}^{+}$and $\mathrm{CD}^{+}$cells on the induction and maintenance of oral tolerance. Cell Immunol 1995;163:19-29.

38 Desvignes C, Bour H, Nicholas JF, et al. Lack of oral tolerance but oral priming for contact senstivity to dinitrofluorobenzene in major histocompatibiltiy antigen deficient mice and in $\mathrm{CD}^{+} \mathrm{T}$ cell-depleted mice. Eur $\mathcal{F}$ Immunol 1996;26:1756-61.

39 Hirahara $\mathrm{K}$, Hisatune T, Nishijima K, et al. $\mathrm{CD} 4^{+} \mathrm{T}$ cells anergized by high dose feeding establish oral tolerance to antibody responses when
transferred in SCID and nude mice. F Immunol 1995;154:6238-45.

40 Garside P, Steel M, Worthey EA, et al. TH2 cells are subject to high-dose oral tolerance and are not essential for its induction. F Immunol 1995;154: 5649-55.

41 Wolvers DAW, van der Cammen MJF. Mucosal tolerance is associated with, but independent of, upregulation of Th2 responses. Immunology 1997;92: 328-33.

42 Jarrett EE. Perinatal influences on IgE responses. Lancet 1984;ii:797-9.

43 Khoruts A, Miller SD, Jenkins MK. Neuroantigen-specific Th2 cells are inefficient suppressors of experimental autoimmune encephalomyelitis induced by effector Th1 cells. F Immunol 1995;155:5011-17

44 Lafaille JJ, Keere FV, Hsu AL, et al. Myelin basic protein-specific T helper 2 (Th2) cells cause experimental autoimmune encephalomyelitis in immuno186:307-12

45 Ding L, Linsley PS, Huang L-Y, et al. IL-10 inhibits macrophage costimulatory activity by selectively inhibiting the upregulation of B7 expression. $\mathcal{F}$ Immunol 1993;3:1224-34.

46 Fiorentino DF, Zlotnik A, Viera P, et al. IL-10 acts on the antigen presenting cell to inhibit cytokine production by Th1 cells. F Immunol 1991;146:344451 .

47 Aroeira LS, Cardillo F, DeAbuquerque DA, et al. Anti-IL-10 treatment does not block either the induction or the maintenance of orally induced tolerance to OVA. Scand F Immunol 1995;41:319-23.

48 Marth T, Strober W, Kelsall BL. High dose oral tolerance in ovalbumin TcR-transgenic mice: systemic neutralisation of interleukin 12 augments TGF $\beta$ secretion and T cell apoptosis. F Immunol 1996;157:2348-57.

49 Symington FW. Lymphotoxin, tumor necrosis factor and gamma interferon are cytostatic for normal human keratinocytes. F Invest Dermatol 1989;92:798-805.

50 Mueller DL, Jenkins MK. Molecular mechanisms underlying functional T-cell unresponsiveness. Curr Opin Immunol 1995;7:375-81.

51 Mowat AMcI, Garside P, Fitton LA, et al. Regulatory activity of endogenous and exogenous transforming growth factor $\beta$ in experimental intestinal immunopathology. Growth Factors 1996;13:75-85.

$52 \mathrm{Kim}$ P-H, Kagnoff MF. Transforming growth factor- $\beta 1$ is a costimulator for IgA production. F Immunol 1990;144:3411-16

53 Roberts A, Sporn M. Physiological actions and clinical applications of transforming growth factor $\beta$ (TGF $\beta)$. Growth Factors $1993 ; 8: 1-9$.

54 Khoury SJ, Hancock WW, Weiner HL. Oral tolerance to myelin basic protein and natural recovery from experimental autoimmune encephalomyelitis are associated with downregulation of inflammatory cytokines and differential upregulation of transfroming growth factor $\beta$, interleukin 4 , and prostaglandin E expression in the brain. $\mathcal{F}$ Exp Med 1992;176:1355-64.

55 Miller A, Lider O, Roberts AB, et al. Suppressor T cells generated by oral tolerization to myelin basic protein suppress both in vitro and in vivo immune responses by the release of transforming growth factor $\beta$ after antigen-specific triggering. Proc Natl Acad Sci USA 1992;89:421-5.

56 Powrie F, Carlino J, Leach MW, et al. A critical role for transforming growth factor- $\beta$ but not interleukin 4 in the suppression of $T$ helper type 2669-74.

57 Neurath MF, Fuss I, Kelsall BL, et al. Experimental granulomatous colitis in mice is abrogated by induction of TGF- $\beta$-mediated oral tolerance. $\mathcal{F}$ Exp Med 1996;183:2605-16.

58 Strober W, Kelsall B, Fuss I, et al. Reciprocal IFN- $\gamma$ and TGF- $\beta$ responses regulate the occurrence of mucosal inflammation. Immunol Today 1997;18: $61-4$

59 Fishman-Lobell J, Friedman A, Weiner HL. Different kinetic patterns of cytokine gene expression in vivo in orally tolerant mice. Eur $\mathcal{F}$ Immunol 1994;24:2720-4.

60 Mowat AMcI, Ferguson A. Hypersensitivity in the small intestinal mucosa. V. Induction of cell mediated immunity to a dietary antigen. Clin Exp Immunology 1981;43:574-82.

61 Mowat AMcI. Deletion of suppressor T cells by 2'-deoxyguanosine abrogates tolerance in mice fed ovalbumin and permits the induction of intestinal delayed-type-hypersensitivity. Immunology 1986;58:179-84.

62 Sands BE, Podolsky DK. Toward new questions in inflammatory bowel disease in 1995. Curr Opin Gastroenterol 1996;12:319-21.

63 Duchmann R, Kaiser I, Hermann E, et al. Tolerance exists towards resident intestinal flora but is broken in active inflammatory bowel disease (IBD). Clin Exp Immunol 1995;102:448-55.

64 Duchmann R, Schmitt E, Knolle P, et al. Tolerance towards resident intestinal flora in mice is abrogated in experimental colitis and restored by treatment with interleukin-10 or antibodies to interleukin-12. Eur $\mathcal{F}$ Immunol 1996;26:934-8.

65 Sadlack B, Merz H, Schorle H, et al. Ulcerative colitis-like disease in mice with a disrupted interleukin-2 gene. Cell 1993;75:253-61.

66 Kuhn R, Lohler J, Rennick D, et al. Interleukin-10-deficient mice develop chronic enterocolitis. Cell 1993;75:263-79.

67 Mombaerts P, Mizoguchi E, Grusby MJ, et al. Spontaneous development of 1993;75:275-82.

68 Moyana TN, Lalonde J-MA Carrageenan-induced intestinal injury in the rat-a model for inflammatory bowel disease. Ann Clin Lab Sci

69 Hermiston ML, Gordon JI. Inflammatory bowel disease and adenomas in mice expressing a dominant negative $\mathrm{N}$-cadherin. Science 1995;270:1203- 
70 Baribault H, Penner J, Iozzo RV, et al. Colorectal hyperplasia and inflammation in keratin 8-deficient FVB/N mice. Genes Dev 1994;8:2964-73.

71 Mashimo H, Wu D-C, Podolsky DK, et al. Impaired defense of intestinal mucosa in mice lacking intestinal trefoil factor. Science 1996;274:262-5.

72 Sayegh MH, Khoury SJ, Hancock WH, et al. Induction of immunity and oral tolerance with polymorphic class II major histocompatibility complex allopeptides in the rat. Proc Natl Acad Sci USA 1992;89:7762-6.

73 Higgins PJ, Weiner H. Suppression of experimental autoimmune encephalomyelitis by oral administration of myelin basic protein and its fragments. f Immunol 1988;140:440-5.

74 Bitar D, Whitacre CC. Suppression of experimental autoimmune encephaomyelitis by the oral administration of myelin basic protein. Cell Immunol 1988;112:364-70.

75 Whitacre CC, Gienapp IE, Zhang X, et al. Oral tolerance in experimental autoimmune encephalomyelitis (EAE): A search for the MBP-specific T cell receptor [abstract]. FASEB F 1990;4:A1856.

76 Meyer AL, Benson JM, Gienapp IE, et al. Suppression of murine chronic relapsing autoimmune encephalomyelitis by the oral administration of relapsing autoimmune encephalomyelitis by the
myelin basic protein. F Immunol 1996;157:4230-8.

77 Yoshino S, Quattrocchi E, Weiner HL. Oral administration of type II collagen suppresses antigen-induced arthritis in Lewis rats. Arthritis Rheum 1995; 38:1092-6.

78 Zhang J Z, Lee CSY, Lider O, et al. Suppression of adjuvant arthritis in Lewis rats by oral administration of type II collagen. F Immunol 1990;145: 2489-93.

79 Nagler-Anderson C, Bober LA, Robinson ME, et al. Suppression of type II collagen-induced arthritis by intragastric administration of soluble type II antigen. Proc Natl Acad Sci USA 1986;83:7443-6.

80 Thompson HS, Staines NA. Could specific oral tolerance be a therapy for autoimmune disease? Immunol Today 1990;11:396-9.

81 Thompson HS, Harper N, Bevan DJ, et al. Suppression of collagen induced arthritis by oral administration of type II collagen: changes in immune and arthritic responses mediated by active peripheral suppression. Autoimmunity 1993;16:189-99.

82 Thompson HS, Staines NA. Gastric administration of type II collagen delays the onset and severity of collagen-induced arthritis in rats. Clin Exp Immunol 1986;64:581-6.

83 Staines NA, Harper N, Ward FJ, et al. Mucosal tolerance and suppression of collagen-induced arthritis (CIA) induced by nasal inhalation of synthetic collagen-induced arthritis (CIA) induced by nasal inhalation of synthetic peptide 184-198 of bovine type II collagen (CII)

84 Thompson SJ, Thompson HS, Harper N, et al. Prevention of pristaneinduced arthritis by the oral administration of type II collagen. Immunology 1993;79:152-7.

85 Nussenblatt RB, Caspi RR, Mahdi R, et al. Inhibition of S-antigen induced experimental autoimmune uveoretinitis by oral induction of tolerance with S-antigen. F Immunol 1990;144:1689-96.

86 Nussenblatt RB, Whitcup SM, De Smet MD, et al. Intraocular inflammatory disease (uveitis) and the use of oral tolerance. A status report. Ann NY Acad Sci 1996;778:325-37.

87 Singh VK, Kalra HK, Yamaki K, et al. Suppression of experimental autoimmune uveitis in rats by the oral administration of the uveitopathogenic S-antigen fragment ar a cross-reactive homologous peptide. Cell Immunol 1992;139:81-90.

88 Thurau SR, Chan CC, Nusenblatt RB, et al. Oral tolerance in a murine model of relapsing experimental autoimmune uveoretinitis: induction of

89 Rizzo LV, Miller-Rivero NE, Chan CC, et al. Interleukin-2 treatment potentiates induction of oral tolerance in a murine model of autoimmunity. 7 Clin Invest 1994;94:1668-72.

90 Drachman DB, Okumura S, Adams RN, et al. Oral tolerance in myaesthenia gravis. Ann NY Acad Sci 1996;778:258-72.

91 Okumura S, McIntosh K, Drachman DB. Oral administration of acetylcholine receptor: effects on experimental myasthenia gravis. Ann Neurol 1994; 36:704-13.
92 Wang ZY, Qiao J, Link H. Suppression of experimental autoimmune myasthenia gravis by oral administration of acetylcholine receptor. $\mathcal{F}$ myasthenia gravis by oral ad

93 Wang Z-Y, He B, Qiao J, et al. Suppression of experimental autoimmune myasthenia gravis and experimental allergic encephalomyelitis by oral administration of acetylcholine receptor and myelin basic protein: double tolerance. F Neuroimmunol 1995;63:79-86.

94 Zhang JA, Davidson L, Eisenbarth G, et al. Suppression of diabetes in NOD mice by oral administration of porcine insulin. Proc Natl Acad Sci USA $1991 ; 88: 10252-6$.

95 Bergerot I, Fioix C, Peterson J, et al. A cholera toxoid-insulin conjugate as an oral vaccine against spontaneous autoimmune diabetes. Proc Natl Acad Sci USA 1997;94:4610-14

96 Bergerot J, Fabien N, Maguer V, et al. Oral administration of human insulin to NOD mice generates CD $4^{+} \mathrm{T}$ cells that suppress adoptive transfer of diabetes. F Autoimmunity 1994;7:655-63.

97 Sayegh MH, Zhang ZJ, Hancock WW, et al. Down-regulation of the immune response to histocompatibility antigen and prevention of sensitization by skin allografts by orally administered alloantigen. Transplantation 1992;53: 163-6.

$98 \mathrm{He}$ YG, Mellon J, Niederkorn JY. The effect of oral immunization on corneal allograft survival. Transplantation 1996;61:920-6.

99 Guimaraes VC, Quintans J, Fisfalen M-E, et al. Suppression of experimental autoimmune thyroiditis by oral administration of thyroglobulin. Endocrinology 1995;136:3353-9.

100 Peterson KE, Braley-Mullen H. Suppression of murine experimental autoimmune thyroiditis by oral administration of porcine thyroglobulin. Cell Immunol 1995;166:123-30.

101 Sieper J, Kary S, Sörensen H, et al. Oral type II collagen treatment in early rheumatoid arthritis. A double blind, placebo-controlled, randomized trial. Arthritis Rheum 1996;39:41-51.

102 Barnett ML, Combitchi D, Trentham DE. A pilot trial of oral type II collagen in the treatment of juvenile rheumatoid arthritis. Arthritis Rheum 1996;39:623-8.

103 Sun JB, Rask C, Olsson T, et al. Treatment of experimental autoimmune encephalomyelitis by feeding myelin basic protein conjugated to cholera toxin B subunit. Proc Natl Acad Sci USA 1996;93:7196-201.

104 Weiner HL. Oral tolerance: Immune mechanisms and treatment of autoimmune disease. Immunol Today 1997;18:335-43.

105 Husby S, Mestecky J, Moldoveanu Z, et al. Oral tolerance in humans: T cell but not B cell tolerance after antigen feeding. F Immunol 1994;152:466370

106 Waldo FB, Van Den Wall Bake AWL, Mestecky J, et al. Suppression of the immune response by nasal immunization. Clin Immunol Immunopathol 1994;72:30-4.

107 Fukaura H, Kent SC, Pietrusewicz ML, et al. Induction of circulating myelin basic protein and proteolipid protein-specific transforming growth factor- $\beta 1$-secreting Th3 cells by oral administration of myelin in multiple sclerosis. F Clin Invest 1996;98:70-7.

108 Weiner HL, Mackin GA, Matsui M, et al. Double-blind pilot trial of tolerization with myelin antigens in multiple sclerosis. Science 1993;259:132124.

109 Trentham DE, Dynesius-Trentham RA, Orav EJ, et al. Effects of oral administration of collagen on rheumatoid arthritis. Science 1993;261:172730.

110 Nussenblatt RB, Gery I, Weiner HL, et al. Treatment of uveitis by oral administration of retinal antigens: Results of a phase I/II randomized masked trial. Am f Opthalmol 1997;123:583-92.

111 Metzler B, Wraith DC. Inhibition of experimental autimmune encephalomyelitis by inhalation but not oral administration of the encephalitogenic peptide: influence of MHC binding affinity. Int Immunol 1993;5:1159-65. 112 Ma S-W, Zhao D-L, Mukherjee R, et al. Transgenic plants expressing
autoantigens fed to mice to induce oral tolerance. Nat Med 1997;3:793-6. 